This item is the archived peer-reviewed author-version of:

Retrospective cohort study on hearing outcome after transmastoid plugging in superior semicircular canal dehiscence syndrome

\title{
Reference:
}

Van Haesendonck Gilles, Van de Heyning Paul, Van Rompaey Vincent.- Retrospective cohort study on hearing outcome after transmastoid plugging in superior semicircular canal dehiscence syndrome

Clinical otolaryngology - ISSN 1749-4478 - Hoboken, Wiley-blackwell, 41:5(2016), p. 601-606

Full text (Publishers DOI): http://dx.doi.org/doi:10.1111/COA.12539

To cite this reference: http://hdl.handle.net/10067/1289990151162165141 
Received Date : 07-Jul-2015

Accepted Date : 10-Sep-2015

Article type :Our Experience

\section{RETROSPECTIVE COHORT STUDY ON HEARING OUTCOME AFTER TRANSMASTOID PLUGGING IN SUPERIOR SEMICIRCULAR CANAL DEHISCENCE SYNDROME.}

SAFE AND EFFECTIVE STRATEGY IN SSCD SYNDROME.

Gilles Van Haesendonck, BM

Paul Van de Heyning, MD, PhD

Vincent Van Rompaey, MD, PhD

Dept. of Otorhinolaryngology and Head \& Neck Surgery, Antwerp University Hospital, Edegem, Belgium.

Faculty of Medicine and Health Sciences, University of Antwerp, Campus Drie Eiken, Antwerp, Belgium.

Corresponding author

Vincent Van Rompaey, MD, PhD

Antwerp University Hospital

Dept. of Otorhinolaryngology and Head \& Neck Surgery

Wilrijkstraat 10, 2650 Edegem, Belgium

vincent.van.rompaey@uza.be

\section{Requests for reprints should be sent to this address.}

None of the authors have financial interests in relation to this work.

This article has been accepted for publication and undergone full peer review but has not been through the copyediting, typesetting, pagination and proofreading process, which may lead to differences between this version and the Version of Record. Please cite this article as doi: $10.1111 /$ coa. 12539

This article is protected by copyright. All rights reserved. 
No financial support was provided toward the completion of this work.

Conflicts of interest: none.

\section{Acknowledgements}

None.

\section{KEY POINTS}

- In case of incapacitating symptoms, surgical treatment can be offered to patients with confirmed superior semicircular canal dehiscence syndrome. Plugging and capping of the superior semicircular canal are most effective in terms of symptom relief. Both the middle fossa and the transmastoid approach have been reported to reach the superior semicircular canal.

- However, the middle fossa approach has potential complications including epidural hematoma, seizures, cerebrospinal fluid leakage, facial palsy, etc. Moreover, plugging through the middle fossa approach has been reported to produce up to $25 \%$ of sensorineural hearing loss.

- In our case series of 12 patients that underwent transmastoid plugging, none of the patients experienced postoperative sensorineural hearing loss. None of the patients experienced epidural hematoma, seizures, cerebrospinal fluid leakage or facial palsy.

- We can confirm the high rate of symptom relief reported in earlier studies on superior semicircular canal plugging, which presents a reliable treatment option to the patient that suffers from incapacitating autophony and hyperacusis of bone-conducted sounds.

- Our results demonstrate that transmastoid plugging of the superior semicircular canal is safe and effective in preserving or improving hearing. No sensorineural hearing loss was observed in our series.

This article is protected by copyright. All rights reserved. 
Keywords: vertigo, semicircular canals, vestibular evoked myogenic potentials.

\section{INTRODUCTION}

The Superior Semicircular Canal Dehiscence Syndrome is a relatively new peripheral inner ear disorder. It is caused by a dehiscence of the bony capsule overlying the superior semicircular canal (SSC), consequently creating a mobile third window to the inner ear. (1) The diagnosis can be made by the combination of the typical history, temporal bone CT-scan and cervical vestibular-evoked myogenic potentials (cVEMP) findings. Symptoms can present isolated or in combination, and include vertigo, hearing loss, autophony and hyperacusis of bone-conducted sounds. Hyperacusis of bone-conducted sounds not only includes pulsatile tinnitus, but might also include hearing one's own eyes or joints move. Often the latter symptoms have to be presented to the patient because they will rarely associate them with diseases related to the ear.

High-resolution multi-detector CT is crucial to detect any dehiscence in the bony capsule of the inner ear. Imaging should be accompanied by evaluation of cVEMPs to confirm the increased responsiveness of the labyrinth induced by the third mobile window lesion by means of electrophysiology.

In case of incapacitating symptoms, surgery can be offered to exclude the mobile third window. The most effective techniques include plugging and capping of the SSC in comparison to resurfacing. (2) Both the middle fossa and the transmastoid approach have been reported to reach the SSC. The main disadvantages of the middle fossa approach are its potential complications including epidural hematoma, facial palsy, seizures, leakage of cerebrospinal fluid, etc. (3) Moreover, plugging through the middle fossa approach has been reported to produce up to $25 \%$ of sensorineural hearing loss (SNHL), although not affecting speech discrimination. (4)

This article is protected by copyright. All rights reserved. 
The primary aim of the study was to gain insight in the effect of transmastoid plugging on postoperative bone and air conduction thresholds as a measure of safety. The secondary aim was to study symptom relief as a measure of effectiveness.

\section{MATERIALS AND METHODS}

Ethics.

The study was designed and conducted according to the Declaration of Helsinki (1996). Ethic committee approval was obtained to report outcome in this population.

Study design.

We performed a retrospective chart review on all consecutive patients who underwent surgery for the SSC dehiscence syndrome from 2008 to 2015. Transmastoid plugging was performed in every case. No patients were lost to follow-up.

\section{Setting.}

Single tertiary referral otology department. The 2 senior authors (PVDH and VVR) performed all surgeries.

\section{Participants and study size.}

All 12 patients that were diagnosed with SSC dehiscence syndrome and underwent transmastoid SSC plugging were included. Eligibility criteria for surgery included incapacitating autophony or hyperacusis of bone-conducted sounds typical to the SSC dehiscence syndrome, temporal bone CT finding of an ipsilateral dehiscent SSC, increased amplitudes and reduced thresholds at cVEMP. We did not operate on SSC dehiscence patients that presented with vertigo as a sole symptom.

This article is protected by copyright. All rights reserved. 


\section{Surgical technique.}

A retroauricular incision is used. Corticosteroids and antibiotics are administered intravenously to provide optimal protection of the labyrinth. A standard mastoidectomy is performed identifying the lateral semicircular canal. The anterior crus of the SSC can be found at a right angle to the anterior part of the lateral semicircular canal (figure 1). The SSC bony capsule has to be skeletonized and blue-lined with a 1-mm diamond burr until the endosteum is visualised. With standard otosclerosis instruments the endosteum is opened. Through the fenestration the endolymphatic duct can now be visualised. A 1-mm fat plug is inserted gently in order to gradually compress the endolymphatic membrane. The fat plug is slowly pushed downwards towards the ampulla to plug the anterior crus. A second plug with bone paté is put on top to secure the fat plug. Subsequently the posterior crus is identified more medially by skeletonizing the inside of the SSC centered on the subarcuate artery. We take care not to enter the posterior crus over $180^{\circ}$ to avoid entering the common crus. After opening the endosteum, we also insert a fat plug and a bone pate plug in the posterior crus and push it towards the location of common crus, without plugging the common crus. The contact between the superior part of the SCC and the middle fossa dura, which creates the dehiscence, can be identified and obliterated with fat plugs as well.

\section{Quantitative variables.}

Preoperative and postoperative audiometry data were collected in a dedicated prospective database and reviewed retrospectively. All audiograms were performed by classified personnel according to the ISO-389 (1975) standard. The guidelines of the Committee on Hearing and Equilibrium for the evaluation of conductive hearing loss were applied. Preoperative and postoperative pure-tone averages (PTAs) were calculated of 500, 1,000, 2,000, and 4,000 Hz, as required. The postoperative ABG was calculated as postoperative air

This article is protected by copyright. All rights reserved. 
conduction (AC) minus postoperative bone conduction (BC). SNHL was defined as a postoperative loss in bone conduction PTA of 1, 2 and $4 \mathrm{kHz}$ exceeding $15 \mathrm{~dB}$ hearing level (dBHL). Amsterdam Hearing Evaluation Plots (AHEPs) are used to report individual cases.

\section{Qualitative variables.}

Preoperative and postoperative symptoms and complications were reviewed in the electronic patient record system and collected in a database.

\section{Bias and statistical methods.}

No obvious sources of bias were identified. No missing outcome data. No comparisons were made.

\section{RESULTS}

Participants.

A total of 12 patients with 13 operations were included in this case series. One patient did not experience enough symptom relief and needed revision. The revision surgery was included as case 1 bis. The latter patient experienced symptom relief after the revision surgery with stable BC thresholds.

\section{Descriptive data.}

The demographics, radiologic classification and symptomatology before and after surgery are listed in table 1. The population consisted of 6 males and 6 females that underwent transmastoid SSC plugging in 6 left $(+1$ revision) and 6 right ears.

This article is protected by copyright. All rights reserved. 
Outcome data.

The audiometric data are listed in table 2. Individual audiometric results are presented in figure 2 .

None of the patients had adverse events such as facial palsy, epidural hematoma, seizures, cerebrospinal fluid leakage. All patients experienced transient nausea due to the sudden obliteration of the SSC. Two patients developed a posterior canal BPPV, which resolved with one Epley manoeuvre.

\section{Main results.}

Overall, a decrease in AC PTA and an increase in BC PTA was observed, resulting in an overall reduction in ABG PTA. None of our patients experienced postoperative SNHL in this study.

A decrease in all five symptoms was seen in this population. This decrease was most obvious in autophony, 11 out of 12 patients suffered from autophony preoperatively and this symptom disappeared in every patient.

\section{DISCUSSION}

\section{Synopsis of key findings}

Discussing the pathophysiology of the SSC dehiscence syndrome with the patient can reassure him or her how the reported symptoms can be explained. In case of incapacitating symptoms, surgical treatment can be offered to separate the labyrinth from the third mobile window.

Initially, the preferred approach to reach the SSC involved the middle fossa craniotomy. However, in 2001 Brantberg described the transmastoid approach, which obviates the need 
for a middle fossa craniotomy and its potential complications such as epidural hematoma, facial nerve injury, cerebrospinal fluid leak and delayed onset of seizures. $(4,5)$

Recurrence of symptoms has been observed in a significant portion of patients undergoing resurfacing. Plugging of the SSC through the middle fossa approach has been reported to enable the highest rate of symptom relief, but was also reported to produce a significant amount of postoperative SNHL in up to $25 \%$ of cases. Therefore we studied the hearing outcome in our group of patients who underwent transmastoid SSC plugging.

We did not observe postoperative SNHL, defined by the Committee guidelines as bone conduction PTA of 1, 2 and $4 \mathrm{kHz}$ exceeding $15 \mathrm{dBHL}$. When studying hearing outcome reported in earlier transmastoid SSC plugging case series only 2 cases (total number of patients 59 , including our series) were reported to have a SNHL. $(5,6)$

\section{Limitations.}

This study has a rather small sample size, although it is the second largest study on transmastoid SSC plugging. Its retrospective nature is a known disadvantage to studies reporting on surgical techniques. However, hearing outcome data was collected in a dedicated prospective audiometry database and no patients were lost to follow-up.

\section{Clinical applicability of this study.}

We can conclude that SSC plugging is a safe technique which not necessarily leads to a detrimental effect on BC or AC thresholds. Even in one revision case, where the SSC was opened again, no SNHL was observed. We can confirm the high rate of symptom relief reported in earlier studies on SSC plugging, which presents a reliable treatment option to the patient that reports incapacitating autophony and hyperacusis of bone-conducted sounds.

This article is protected by copyright. All rights reserved. 


\section{CONCLUSION}

This study has demonstrated the safety and effectiveness of transmastoid plugging in case of incapacitating symptoms produced by a confirmed SSC dehiscence syndrome. It is safe to the cochlea and effective because of its high rate of symptom relief. The transmastoid approach also avoids the potential complications related to the middle fossa approach.

\section{REFERENCES}

1. Minor LB, Solomon D, Zinreich JS, Zee DS. Sound- and/or pressure-induced vertigo due to bone dehiscence of the superior semicircular canal. Arch Otolaryngol Head Neck Surg 1998; 124: 249-58.

2. Vlastarakos PV, Proikas K, Tavoulari E, Kikidis D, Maragoudakis P, Nikolopoulos TP. Efficacy assessment and complications of surgical management for superior semicircular canal dehiscence: a meta-analysis of published interventional studies. Eur Arch Otorhinolaryngol 2009; 266: 177-86.

3. Niesten ME, McKenna MJ, Grolman W, Lee DJ. Clinical factors associated with prolonged recovery after superior canal dehiscence surgery. Otol Neurotol 2012; 33: 824-31.

4. Ward BK, Agrawal Y, Nguyen E, Della Santina CC, Limb CJ, Francis HW, et al. Hearing outcomes after surgical plugging of the superior semicircular canal by a middle cranial fossa approach. Otol Neurotol 2012; 33: 1386-91.

5. Brantberg K, Bergenius J, Mendel L, Witt H, Tribukait A, Ygge J. Symptoms, findings and treatment in patients with dehiscence of the superior semicircular canal. Acta Otolaryngol 2001; 121: 68-75.

6. Zhao YC, Somers $\mathrm{T}$, van Dinther J, Vanspauwen R, Husseman J, Briggs R. Transmastoid repair of superior semicircular canal dehiscence. J Neurol Surg B Skull Base 2012; 73: 225-9.

This article is protected by copyright. All rights reserved. 


\section{FIGURES}

Figure 1. Transmastoid plugging of the posterior crus of the right SSC. 1, lateral semicircular canal; 2, middle fossa dura; 3 , subarcuate fossa; 4, the SSC bony capsule has to be skeletonized and blue-lined with a 1-mm diamond burr; 5 , the endosteum is visualised; 6 , with standard otosclerosis instruments the endosteum is opened; 7, a 1-mm fat plug is inserted gently in order to gradually compress the endolymphatic membrane; 8 , the fat plug is slowly pushed downwards towards the location of common crus, without plugging the common crus; 9 , bone paté is used to obliterate the SSC superior to the fat plug.

Figure 2. Amsterdam Hearing Evaluation Plot on $B C$ thresholds and $A B G$ closure. $A, B C$ thresholds. Preoperative BC plotted against postoperative BC for each operated ear. The 2 diagonal lines enclose the area within $\mathrm{BC}$ that did not change over more than $10 \mathrm{dBHL}$. B, ABG closure Postoperative gain in $A C$ plotted against the preoperative $A B G$ for each operated ear. The solid diagonal line indicates total closure of the gap between preoperative $\mathrm{AC}$ and BC. Every point below this line is defined as overclosure. The dotted diagonal line indicates a negative change in $\mathrm{AC}$ or a change in $\mathrm{AC}$ that was not enough to close the gap between postoperative $\mathrm{AC}$ and preoperative $\mathrm{BC}$ to $20 \mathrm{dBHL}$ or less.

This article is protected by copyright. All rights reserved. 


\section{TABLES}

Table 1. Demographics including sex, age, side, follow-up period and radiologic classification of the dehiscence location. Symptomatology before and after surgery F, female; M, Male; L, left; R, right; mo, month; y, year.

\begin{tabular}{|c|c|c|c|c|c|c|c|c|c|c|c|c|c|c|c|}
\hline \multirow[t]{2}{*}{$\begin{array}{l}\text { patie } \\
\text { nt }\end{array}$} & \multirow[t]{2}{*}{ sex } & \multirow[t]{2}{*}{ age } & \multirow[t]{2}{*}{ side } & \multirow[t]{2}{*}{$\begin{array}{l}\text { follow } \\
\text { up }\end{array}$} & \multirow[t]{2}{*}{$\begin{array}{l}\text { radiologic } \\
\text { classification }\end{array}$} & \multicolumn{2}{|c|}{$\begin{array}{l}\text { autopho } \\
\text { ny }\end{array}$} & \multicolumn{2}{|c|}{ Tullio } & \multicolumn{2}{|c|}{$\begin{array}{l}\text { pressure } \\
\text {-induced } \\
\text { vertigo }\end{array}$} & \multicolumn{2}{|c|}{$\begin{array}{l}\text { pulsatil } \\
\text { e } \\
\text { tinnitus }\end{array}$} & \multicolumn{2}{|c|}{$\begin{array}{l}\text { hyperacu } \\
\text { sis }\end{array}$} \\
\hline & & & & & & $\begin{array}{l}\mathrm{pr} \\
\mathrm{e}\end{array}$ & $\begin{array}{l}\text { pos } \\
\mathrm{t}\end{array}$ & $\begin{array}{l}\mathrm{pr} \\
\mathrm{e}\end{array}$ & $\begin{array}{l}\text { pos } \\
\mathrm{t}\end{array}$ & $\begin{array}{l}\mathrm{pr} \\
\mathrm{e}\end{array}$ & post & $\begin{array}{l}\mathrm{pr} \\
\mathrm{e}\end{array}$ & $\begin{array}{l}\text { po } \\
\text { st }\end{array}$ & $\begin{array}{l}\mathrm{pr} \\
\mathrm{e}\end{array}$ & post \\
\hline 1 & $\mathrm{~F}$ & 42 & $\mathrm{~L}$ & $1 \mathrm{mo}$ & arcuate eminence & 1 & 1 & 0 & 0 & 0 & 0 & 0 & 0 & 1 & 1 \\
\hline 1 bis & $\mathrm{F}$ & 43 & $\mathrm{~L}$ & $1 \mathrm{mo}$ & arcuate eminence & 1 & 0 & 0 & 0 & 0 & 0 & 0 & 0 & 1 & 0 \\
\hline 2 & $\mathrm{~F}$ & 61 & $\mathrm{R}$ & $6 \mathrm{mo}$ & arcuate eminence & 1 & 0 & 0 & 0 & 0 & 0 & 1 & 0 & 1 & 0 \\
\hline 3 & $\mathrm{~F}$ & 50 & $\mathrm{~L}$ & $6 \mathrm{mo}$ & - & 1 & 0 & 1 & 0 & 0 & 0 & 1 & 0 & 0 & 0 \\
\hline 4 & M & 49 & $\mathrm{~L}$ & $2 y$ & arcuate eminence & 1 & 0 & 1 & 0 & 0 & 1 & 1 & 1 & 1 & 0 \\
\hline 5 & M & 54 & $\mathrm{~L}$ & $6 \mathrm{mo}$ & lateral upslope & 1 & 0 & 1 & 1 & 0 & 0 & 1 & 0 & 0 & 0 \\
\hline 6 & $\mathrm{~F}$ & 53 & $\mathrm{R}$ & $1 \mathrm{y}$ & arcuate eminence & 1 & 0 & 0 & 0 & 1 & 0 & 0 & 0 & 1 & 1 \\
\hline 7 & $\mathrm{~F}$ & 48 & $\mathrm{R}$ & $1 \mathrm{y}$ & lateral upslope & 1 & 0 & 0 & 0 & 1 & 1 & 1 & 1 & 1 & 0 \\
\hline 8 & M & 43 & $\mathrm{R}$ & $1 \mathrm{mo}$ & $\begin{array}{l}\text { superior petrosal } \\
\text { sinus associated } \\
\text { SCD }\end{array}$ & 1 & 0 & 1 & 0 & 1 & 1 & 1 & 0 & 0 & 0 \\
\hline 9 & $\mathrm{~F}$ & 61 & $\mathrm{~L}$ & $2 \mathrm{mo}$ & lateral upslope & 1 & 0 & 0 & 0 & 0 & 0 & 1 & 1 & 1 & 0 \\
\hline 10 & M & 47 & $\mathrm{R}$ & $1 \mathrm{mo}$ & lateral upslope & 0 & 0 & 0 & 0 & 0 & 0 & 1 & 0 & 0 & 0 \\
\hline 11 & M & 52 & $\mathrm{~L}$ & $1 \mathrm{mo}$ & - & 1 & 0 & 1 & 0 & 1 & 0 & 1 & 0 & 0 & 0 \\
\hline 12 & M & 54 & $\mathrm{~L}$ & $1 \mathrm{mo}$ & arcuate eminence & 1 & 0 & 0 & 0 & 1 & 1 & 0 & 0 & 1 & 0 \\
\hline
\end{tabular}

This article is protected by copyright. All rights reserved. 
Table 2. Individual audiometric data in dBHL. AC, air conduction; BC, bone conduction; PTA, pure-tone average; pre, preoperative; post, postoperative.

\begin{tabular}{|l|l|l|l|l|l|l|l|l|l|}
\hline $\begin{array}{l}\text { Patie } \\
\text { nt }\end{array}$ & $\begin{array}{l}\text { AC } \\
\text { PTA } \\
\text { pre }\end{array}$ & $\begin{array}{l}\text { AC } \\
\text { PTA } \\
\text { post }\end{array}$ & $\begin{array}{l}\text { differe } \\
\text { nce }\end{array}$ & $\begin{array}{l}\text { BC } \\
\text { PTA } \\
\text { pre }\end{array}$ & $\begin{array}{l}\text { BC } \\
\text { PTA } \\
\text { post }\end{array}$ & $\begin{array}{l}\text { differe } \\
\text { nce }\end{array}$ & $\begin{array}{l}\text { PTA } \\
\text { ABG } \\
\text { pre }\end{array}$ & $\begin{array}{l}\text { PTA } \\
\text { ABG } \\
\text { post }\end{array}$ & $\begin{array}{l}\text { differe } \\
\text { nce }\end{array}$ \\
\hline $\mathbf{1}$ & 17 & 8 & 9 & 4 & 11 & -8 & 15 & 0 & 15 \\
\hline $\mathbf{1}$ bis & 19 & 6 & 13 & 4 & 0 & 4 & 15 & 6 & 9 \\
\hline $\mathbf{2}$ & 9 & 13 & -4 & 1 & 13 & -11 & 8 & 0 & 8 \\
\hline $\mathbf{3}$ & 50 & 39 & 11 & 38 & 28 & 10 & 13 & 11 & 1 \\
\hline $\mathbf{4}$ & 8 & 11 & -4 & 8 & 11 & -4 & 0 & 0 & 0 \\
\hline $\mathbf{5}$ & 29 & 23 & 6 & 19 & 18 & 1 & 10 & 5 & 5 \\
\hline $\mathbf{6}$ & 26 & 26 & 0 & 14 & 21 & -8 & 13 & 5 & 8 \\
\hline $\mathbf{7}$ & 49 & 36 & 13 & 11 & 20 & -9 & 38 & 16 & 21 \\
\hline $\mathbf{8}$ & 30 & 16 & 14 & 11 & 6 & 5 & 19 & 10 & 9 \\
\hline $\mathbf{9}$ & 25 & 25 & 0 & 25 & 16 & 9 & 0 & 9 & -9 \\
\hline $\mathbf{1 0}$ & 26 & 26 & 0 & 14 & 24 & -10 & 13 & 3 & 10 \\
\hline $\mathbf{1 1}$ & 10 & 13 & -3 & 10 & 13 & -3 & 0 & 0 & 0 \\
\hline $\mathbf{1 2}$ & 19 & 18 & 1 & 11 & 16 & -5 & 8 & 1 & 6 \\
\hline medi & 25 & 18 & 1 & 11 & 16 & -4 & 13 & 5 & 8 \\
\hline $\mathbf{a n}$ & & & & & & & & & \\
\hline
\end{tabular}
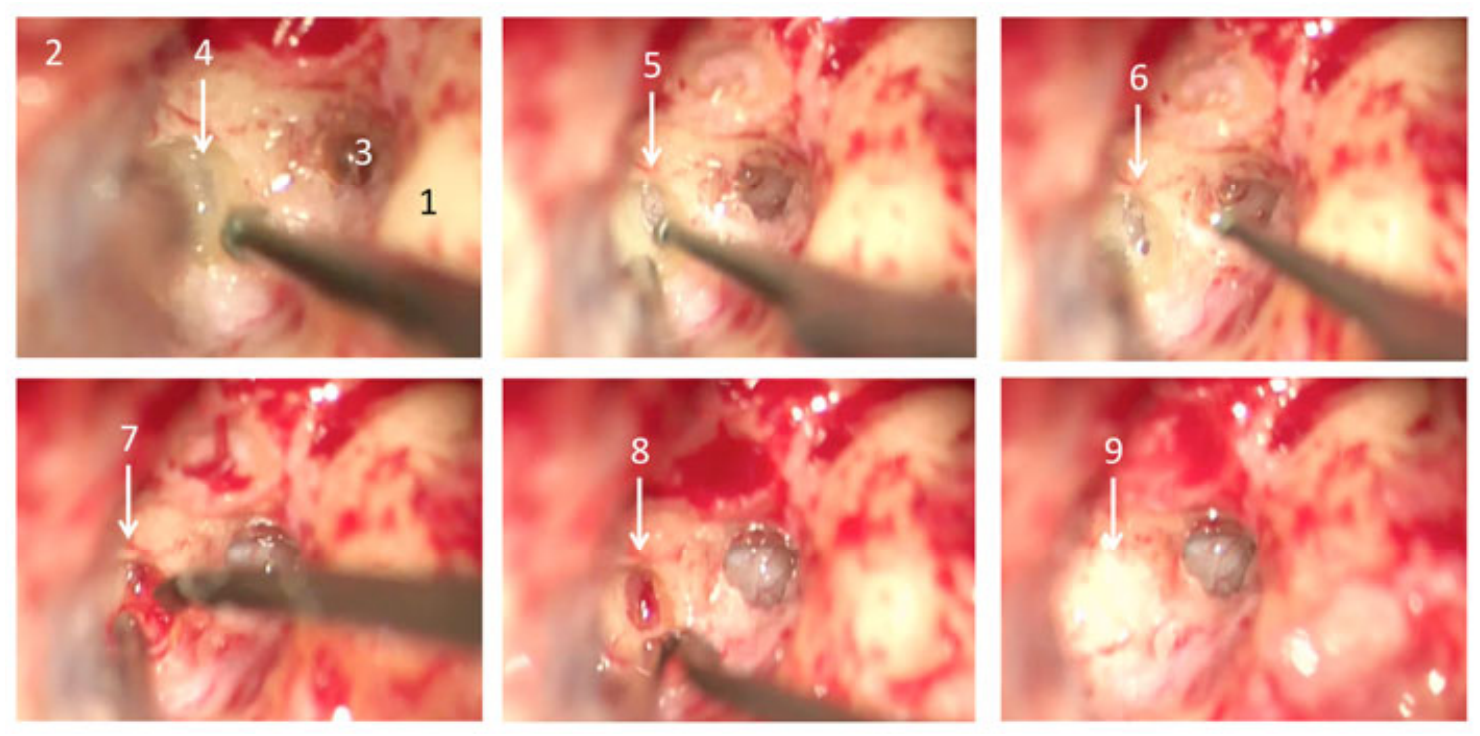

This article is protected by copyright. All rights reserved. 
A

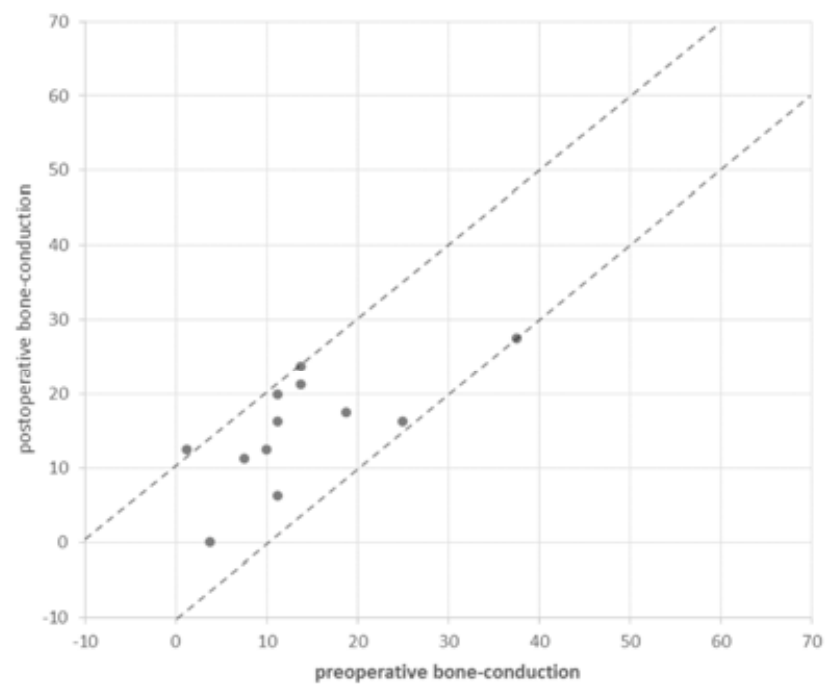

B

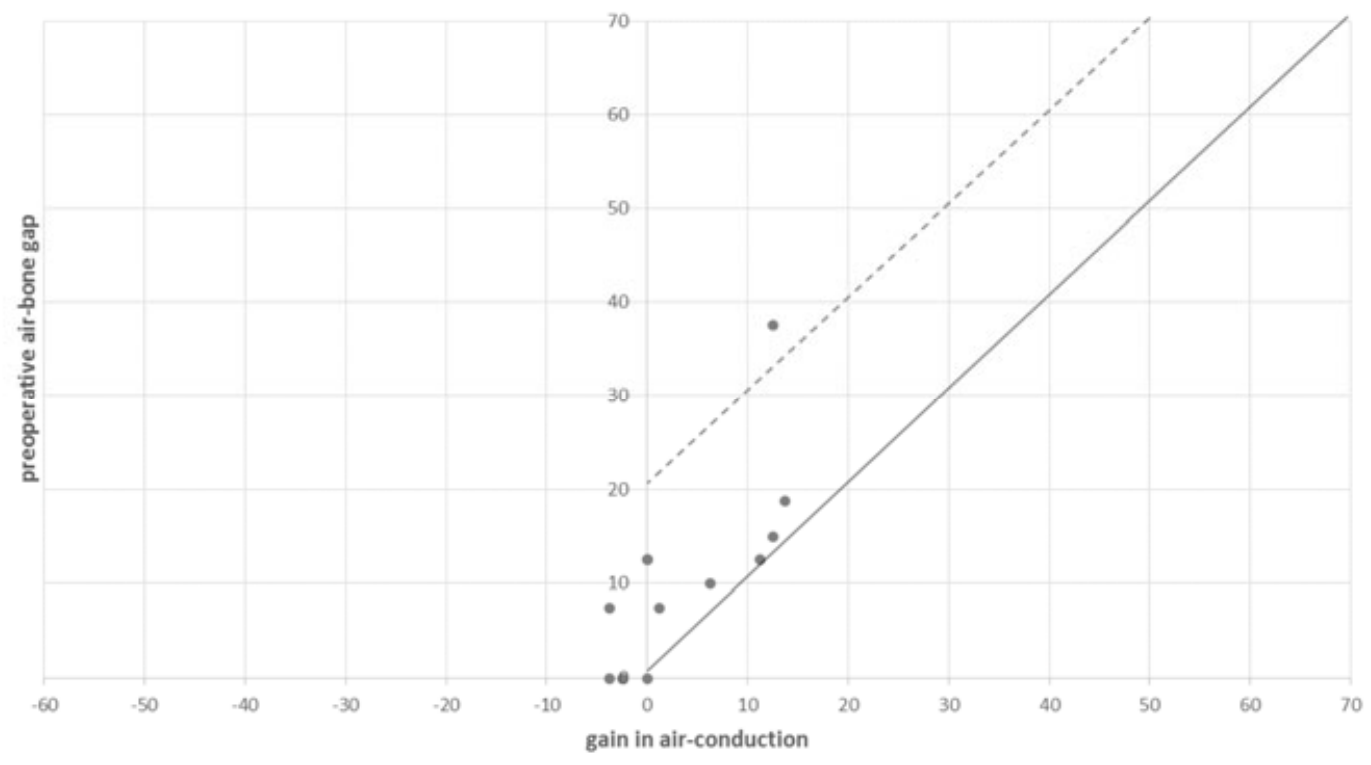

This article is protected by copyright. All rights reserved. 